\title{
Top Evidentiary Gaps in Managed Care Pharmacy: A Research Agenda
}

\author{
Jody Gembarski, PharmD; Joseph Couto, MBA, PharmD; Marcus Wilson, PharmD; \\ and Contributors from the Joint Research Committee of AMCP and the AMCP Foundation
}

\begin{abstract}
SUMMARY
Research agendas play valuable roles in clearly identifying high-priority topics that reflect potential to improve health care quality. The purpose of this report is to present work completed by the Academy of Managed Care Pharmacy (AMCP) and AMCP Foundation Joint Research Committee. This committee set forth to develop a research agenda for our 2 organizations that focuses on critical evidence needs in managed care pharmacy. This document reviews results from 2 surveys that were conducted to better understand unmet research needs within managed care pharmacy and to inform professional efforts of managed care pharmacists. The first survey collected qualitative data from key opinion leaders (KOLs) regarding the top evidentiary gaps in managed care pharmacy and barriers to closing those gaps. The second survey was sent to AMCP members and AMCP Foundation stakeholders, used a mixed methods quantitative-qualitative design, and incorporated concepts from initial KOL responses. The key outcome from these proceedings is the research agenda, which identifies and prioritizes 4 evidentiary gaps in managed care pharmacy: (1) real-world evidence to inform managed care pharmacy decision making, (2) valuebased models in managed care pharmacy to address total cost of care, (3) impact of benefit design or utilization management strategies on patient outcomes, and (4) impact of direct patient care services provided by managed care pharmacy on patient outcomes. The agenda was intended to be broad and will evolve over time. AMCP and the AMCP Foundation hope that this research agenda inspires the AMCP membership, researchers, and funding agencies to close these gaps in knowledge and understanding.
\end{abstract}

J Manag Care Spec Pharm. 2020;26(4):375-81

Copyright $\odot 2020$, Academy of Managed Care Pharmacy. All rights reserved.

A research agenda identifies high-priority topics not presently reinforced with an adequate evidence base. Articulating a research agenda, and then creating opportunities to generate more data within the agenda, can close evidence gaps.

The constant flux of U.S health care demands that managed care pharmacy anticipate and prepare for changes in policy, technology, and clinical practice. Managed care pharmacy must remain vigilant to ensure informed decision making, and proper patient access to health care services must be supported by comprehensive research. Payers have indicated a high degree of interest in data to support forecasting, total medical cost and resource offsets, and quality and outcomes performance. ${ }^{1}$ However, to date, no consensus statement on the evidentiary needs of our field has been published.

\section{AMCP, AMCP Foundation, and the Joint Research Committee}

Managed care pharmacy principles are based on the use of scientific evidence to optimize health outcomes, while making the best use of health care dollars allocated to medications and their management. The Academy of Managed Care Pharmacy (AMCP) empowers members to improve patient health by ensuring access to high-quality, cost-effective medications and other therapies. The AMCP Foundation mission is to advance the quality and affordability of health care by promoting the application of medication-related research and education. Specific to research, the AMCP Foundation aims to enhance the collective knowledge about how managed care pharmacy impacts patient outcomes.

The AMCP and AMCP Foundation Joint Research Committee was established in 2016. The committee objective is to promote and encourage the creation and dissemination of relevant, credible research and initiatives to advance patient care services in managed care pharmacy to ultimately improve health care for all. The Joint Research Committee led the development of the research agenda described in these proceedings. The AMCP Board of Directors and AMCP Foundation Board of Trustees reviewed and approved the research agenda.

This report details the process used to survey stakeholders within managed care pharmacy to identify evidence gaps and to develop a research agenda that also included the prioritization of key topics.

\section{Capturing the Voice of Managed Care Pharmacy}

Research prioritization has been practiced by many organizations to advance goals and needs of constituents. Since established guidelines for research prioritization do not exist, various methods have been used to determine research agendas. For example, the American College of Clinical Pharmacy developed such an agenda in 2005 by having their leadership generate ideas that were validated and refined by domain panels that consisted of their membership. ${ }^{2}$ In another instance, the Institute of Medicine (IOM) used substantial public input and followed a multistage process of individual and collective deliberation to generate 100 priority topics for comparative effectiveness research (CER) in 2009. ${ }^{3}$ A past editor of the Annals of Internal Medicine, who led IOM efforts to develop CER priorities, stated that the methodology behind this agenda 


\section{FIGURE 1 Methods}

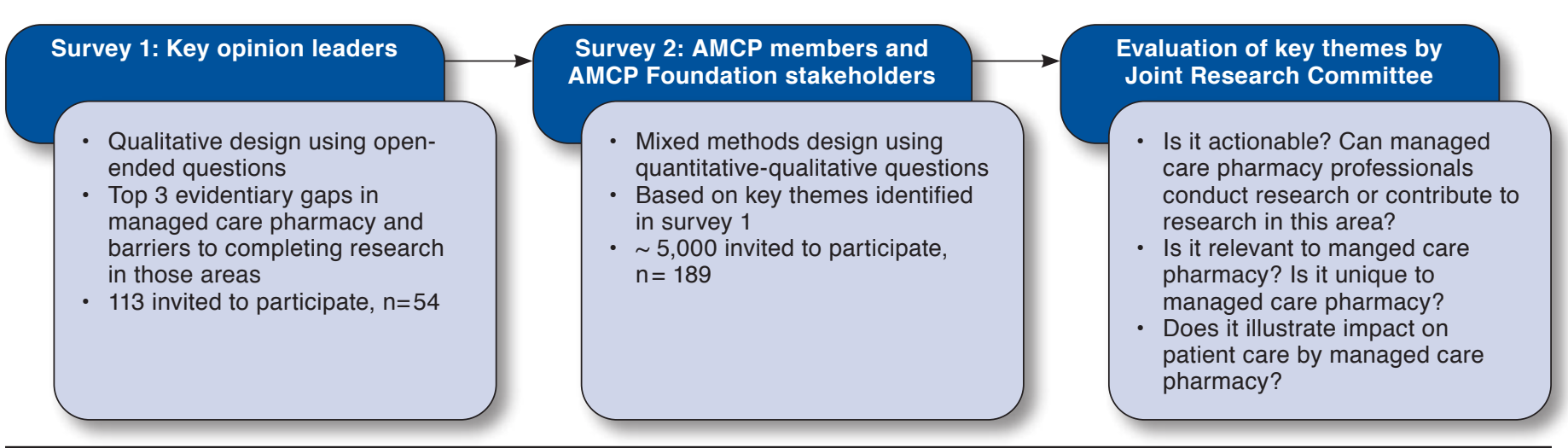

AMCP = Academy of Managed Care Pharmacy.

could have been improved by getting more input from people at the frontlines of health care. ${ }^{4}$ The goal of the Joint Research Committee was to determine pressing issues faced by frontline professionals of managed care pharmacy. Thus, a two-pronged survey approach was used to develop the research agenda.

\section{Methodology}

Two surveys were conducted sequentially to understand the evidentiary needs of the field (Figure 1).5,6

The first survey targeted a convenience sample of key opinion leaders (KOLs) with open-ended, descriptive questions that collected qualitative data. One-hundred thirteen individual KOLs recommended by members of the Joint Research Committee and AMCP/Foundation staff were invited to participate in the survey. KOLs included representatives from the AMCP Board of Directors, AMCP Foundation Board of Trustees, and the Journal of Managed Care \& Specialty Pharmacy Editorial Advisory Board. This sample of KOLs was chosen based on likelihood to respond, knowledge of research relevant to managed care pharmacy, and diversity of experience within respective areas of expertise.

Participants were asked for viewpoints on the top 3 evidentiary gaps in managed care pharmacy and barriers to completing research in those areas. Conventional content analysis was used to determine codes that were reflective of textual data. These codes were then sorted into categories based on linkages, with subsequent organization of categories into meaningful clusters. At least 3 reviewers participated in each round of coding and analysis to limit bias.

Initial survey responses served as the basis to develop a second cross-sectional survey that was sent to AMCP members and AMCP Foundation stakeholders. This second survey incorporated concepts from the KOL responses into a multiple choice, mixed qualitative-quantitative web-based survey with a comment section. This inquiry was intended to corroborate and refine the areas identified by KOLs, while flagging any additional areas that were not captured in the initial survey.

\section{Respondent Demographics}

Figure 2 illustrates the distribution by employer type of survey respondents, as well as AMCP active and associate members. The surveys effectively captured perspectives from individuals working in the main employer types represented within AMCP's membership: academic institutions; consulting companies; health plans or payers; health care providers, including those represented by accountable care organizations (ACOs) and integrated delivery networks; pharmaceutical manufacturers; and other.

The initial survey had a $46 \%$ response rate $(n=54)$. Among respondents, health plans and payers had the highest representation (37\%), followed by academic institutions (17\%) and those selecting other (17\%).

The second survey had a 3\% response rate $(n=189)$, typical for nonincentivized, email-based surveys that usually range from $1 \%$ to $30 \%{ }^{7,8}$ The majority of respondents were pharmacists (63\%) or researchers (19\%). Respondents in the second survey were primarily employed by health plans and payers (47\%), manufacturers (19\%), and consulting companies (13\%).

\section{Key Themes in Survey Results}

Key themes were derived by grouping individual results from the initial survey into broader categories of perceived evidentiary gaps in managed care pharmacy. Final categories following content analysis were as follows: real-world evidence, value-based care delivery, benefit design, comparative drug data, and the value of medication therapy management (Figure 3). 


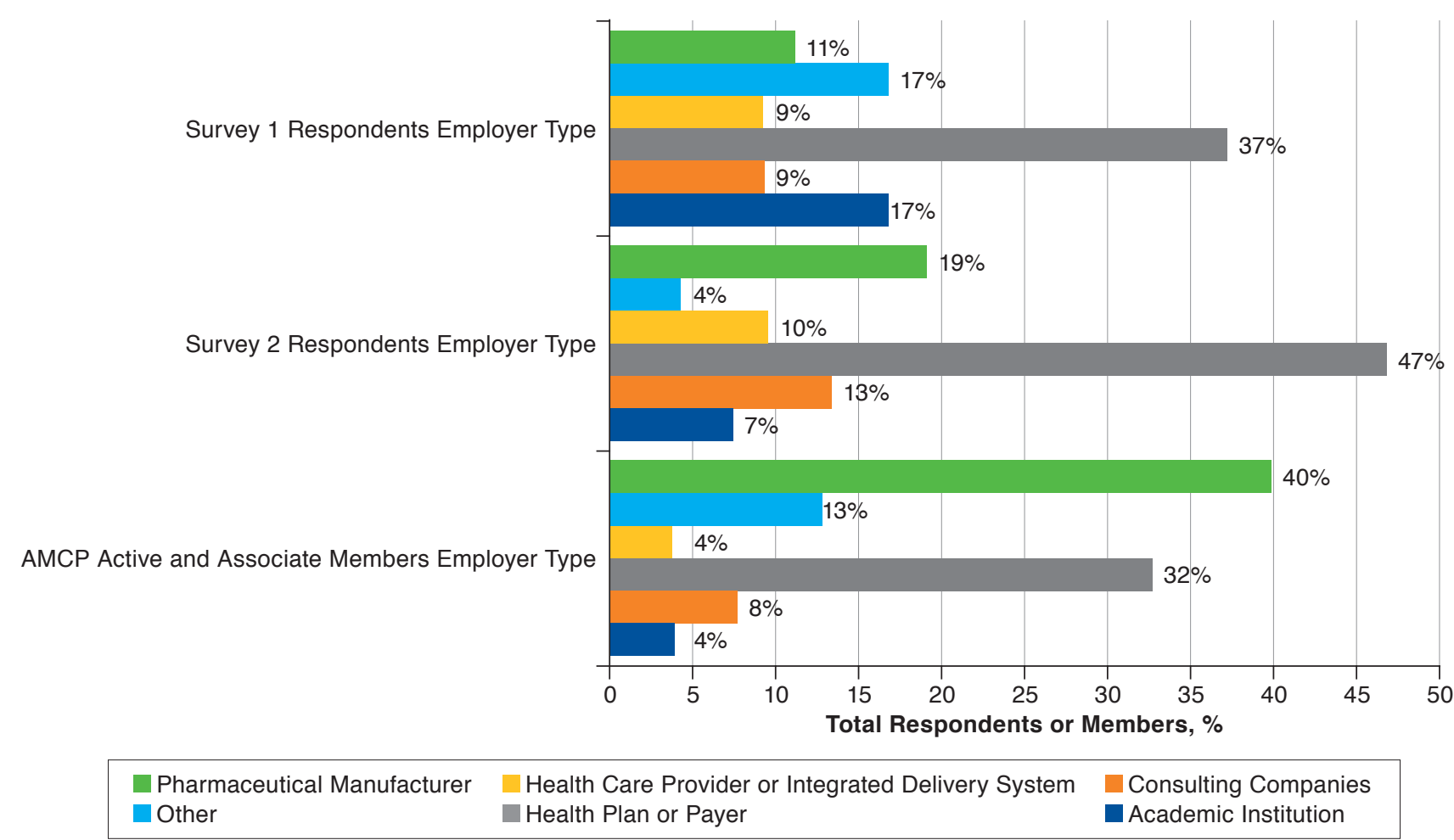

AMCP $=$ Academy of Managed Care Pharmacy.

The second survey assessed the degree to which respondents concurred with these themes and their relative importance. Within this survey (Figure 3), value-based decision making was said to have the greatest research-related needs (27\%), and real-world evidence was nearly as compelling (25\%). The second survey was important to ensure that results were generalizable to encompass all managed care pharmacy stakeholders.

These topics were refined by the committee to create a final research agenda that targets evidentiary gaps highly relevant to managed care pharmacy-areas that are actionable with significant potential to impact patient care.

\section{Research Agenda}

Results from both surveys were reviewed by the Joint Research Committee to evaluate relevance to managed care pharmacy, actionability, and impact on patient care. The committee developed the research agenda (Figure 4), which emphasizes research opportunities where managed care pharmacy can directly lead and influence.

This 4-part research agenda highlights critical gaps in the existing literature and should stimulate AMCP members, researchers, and funding agencies to address these gaps.
High-quality research aligned with this agenda will further drive the following: (a) efficient benefit designs, (b) innovative utilization management strategies, and (c) cost-effective patient care services that improve health outcomes.

\section{Prioritization Strategy}

This research agenda is purposely broad to allow fluidity in response to the rapid evolution of U.S. health care, technology advances, and data capabilities. Given the agenda's broad nature and to provide guidance to interested stakeholders, the Joint Research Committee recommends prioritizing research topics on certain types of drugs or clinical care services (Figure 4).

\section{Research Agenda Discussion: Real-World Evidence to} Inform Managed Care Pharmacy Decision Making

\section{Integration of Medical and Pharmacy Data}

Integrating medical and pharmacy data is necessary to determine the true value and cost-effectiveness of a patient intervention or benefit design. For example, investing resources into a program to improve medication adherence increases administrative and pharmacy costs. However, if these investments subsequently reduce medical costs (e.g., hospitalizations and 


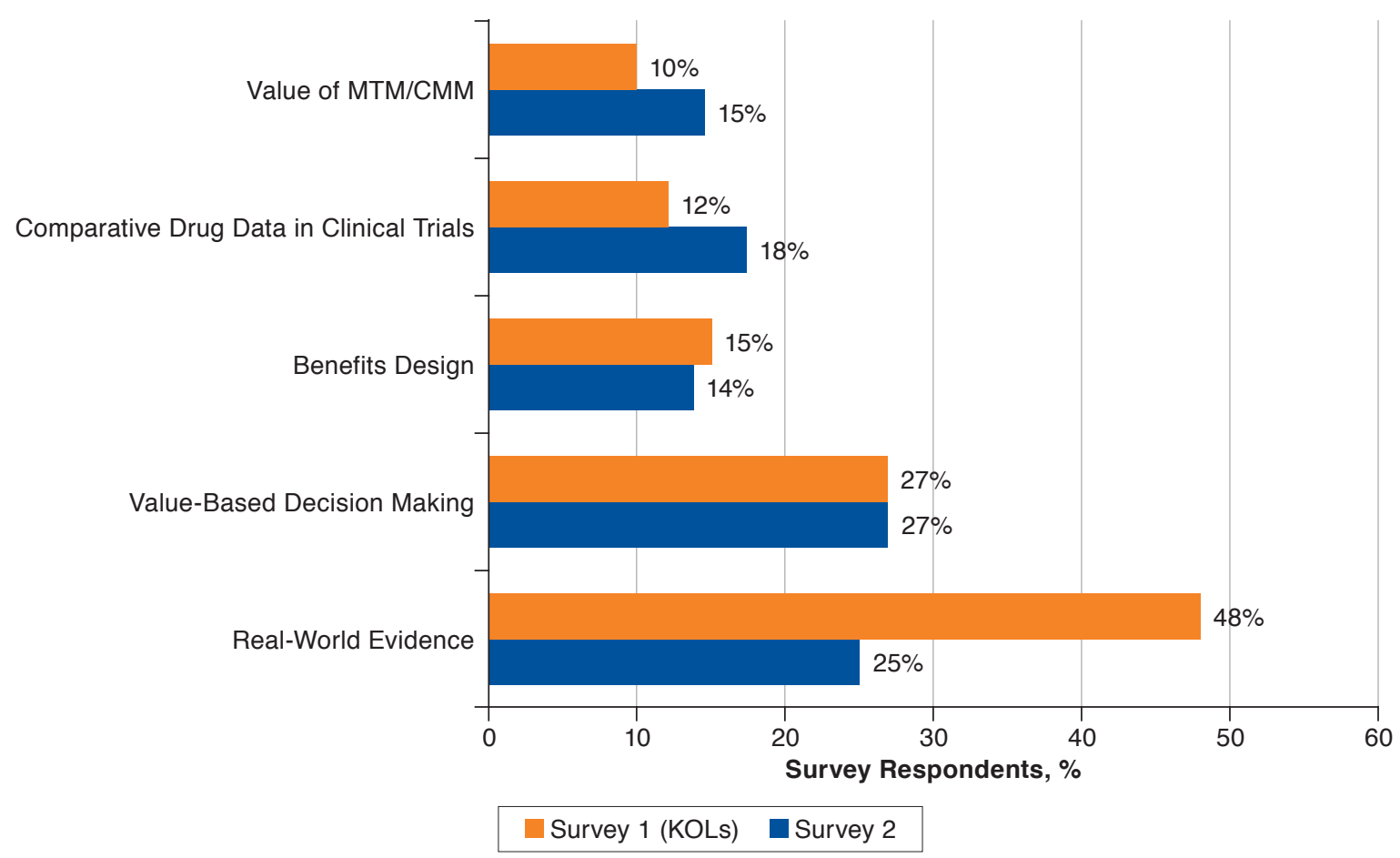

$C M M=$ comprehensive medication management; $K O L=$ key opinion leader; $M T M=$ medication therapy management.

emergency room visits), then the investment may be worthwhile to reduce total health care costs. Research describing total cost of care is needed as managed care organizations (MCOs) make decisions about resource allocation. This information can inform benefit design, which in turn can balance costs with the provision of appropriate, evidence-based care.

\section{Long-Term Safety and Effectiveness Data}

Clinical studies often evaluate short-term efficacy or safety, since this is less time-consuming and less costly, yet long-term outcomes are typically of greater interest to payers and providers. Safety and efficacy data generated from clinical trials are valuable, but the trials' highly controlled environments are difficult to recreate in clinical practice. Furthermore, the study populations represented in the clinical trial may not apply to the general population, requiring health care professionals to extrapolate available data to meet their needs. Examining clinical and financial outcomes under real-world conditions is necessary to fill these gaps in knowledge.

\section{Relationship of Surrogate Markers to Long-Term Clinical Outcomes}

Surrogate markers are often used in clinical trials as a substitute for a clinically meaningful outcome. Using surrogate markers in early drug development is appropriate and accepted to help guide regulatory decision making. ${ }^{9}$ In practice, it is more beneficial to determine if a statistically significant change in a surrogate marker translates into a clinically meaningful outcome. For example, a drug may lower hemoglobin Alc but is that change enough to reduce cardiovascular risk years later? Research focused on long-term clinical outcomes such as reduced morbidity and mortality are time consuming and costly, yet, extremely valuable to patients' care and management. With ongoing improvements in technology and data management, performing longitudinal studies should demand fewer resources. However, these types of studies have yet to become abundant in the literature.

\section{Value-Based Models in Managed Care Pharmacy to Address Total Cost of Care}

Value can be broadly defined as the clinical and humanistic outcomes resulting from a particular treatment as a function of the cost of that therapy.

Value-Based Decision Making. Value-based decision making involves using patient outcomes and the total cost of care over a given time horizon to give insight into benefit design, utilization management programs, care access, wellness programs, 


\section{FIGURE 4 Research Agenda and Prioritization} Strategy

Research agenda elements

1. Real-world evidence to inform managed care pharmacy decision making

2. Value-based models in managed care pharmacy to address total cost of care

3. Impact of benefit design or utilization management strategies on patient outcomes

4. Impact of direct patient care services provided by managed care pharmacy on patient outcomes

\section{Prioritize by types of drugs or} clinical care services

- Those approved under the FDA's Fast Track, Breakthrough Therapy, or Accelerated Approval categories that have very limited clinical or economic evidence at the time of launch

- Whose price and/or expected use would have a significant impact on the managed care pharmacy budget

- Where potential opportunities for outcomes-based contracting exist

- Impacted by legislative activities and policies, (e.g., preventive care)

- Indicated in disease states where there are limited or outdated clinical guidelines

- MTM and the impact on clinical outcomes across various patient demographics

FDA =U.S. Food and Drug Administration; MTM=medication therapy management.

and other aspects of the coverage offered by MCOs. While clinical trials can inform some of these decisions, additional data are often required to incorporate concepts such as the dynamic nature of care delivery, health plan patient turnover, and the complexity of drug pricing. Data from clinical practice (such as those derived from medical claims or electronic health records) and decision analytic models can often provide more specific and relevant insights to MCOs. Research that captures total cost of care and more comprehensive health outcomes are seen as particularly useful and are becoming more commonplace.

Value frameworks published by organizations such as the American Society of Clinical Oncology and the Institute for Clinical and Economic Review can help bring insights into value-based decision making. ${ }^{10,11}$ Frameworks attempt to synthesize the costs incurred and outcomes delivered by pharmaceuticals in a particular therapeutic area. Research that describes the validity and impact on decision making of any of these information sources or concepts is needed to reinforce their use.
Value-Based Contracting. An extension of value-based decision making is tying a value outcome to contractual pricing or reimbursement between payers, care providers, and/or manufacturers. Because availability and reliability of outcomes data varies greatly, contracts may vary considerably from drug to drug and between disease states. In addition, the financial aspects of these contracts are also heavily influenced by government pricing rules (e.g., Medicaid best price). Research is needed to show the clinical and economic impact of specific programs; however, contractual restraints often preclude MCOs from publishing detailed results. Broader research on aspects of value-based contracts, such as methods used to determine outcomes or the impact on total cost of care, should be encouraged in an effort to share best practices.

\section{Benefit Design and Utilization Management}

Impact of Benefit Design on Clinical and Economic Outcomes. MCOs design benefit packages to help control health care expenditure, while also providing appropriate and necessary care. Each benefit package identifies services that are included in coverage and applicable patient cost share. The design of the benefit may include a high deductible, require a referral for care or higher cost share on select services and drugs, or waive cost sharing on preventive drugs and services, for example. All of these designs impact overall health spending as well as patient outcomes.

Higher patient cost share can deter use of less effective services and drugs. However, if those services are unavoidable, it can place a financial burden on the patient and may prevent or limit access to care. Conversely, waiving cost sharing on preventive medications is an attempt to increase access to preventive treatments that will lessen disease complications and comorbidities and likely lead to lower total health care costs in the future. Further research is needed to determine how different benefit designs impact patient behavior, use of care, total cost of care, and health outcomes.

Impact of Formulary Utilization Management on Patient Outcomes and Health Care Costs. MCOs apply utilization management (such as prior authorization, step therapy, and quantity limits) to guide use of the most cost-effective therapeutic options. Restrictions at the point of sale require the prescriber and health plan to collaborate in providing appropriate and affordable access to care. In the event that coverage of the initially prescribed medication is not pursued, what is the impact on patient care? An alternative may be prescribed or the patient may go without treatment.

In addition to rising drug costs and inflation, MCOs are faced with the challenge of expedited drug approvals with limited data available at market launch, ${ }^{12}$ as well as drugs promoted through direct-to-consumer advertising. Utilization management is a tool used by MCOs to help mitigate these 
pressures; however, research is needed that describes impact on patient care.

\section{Patient Care Services: Medication Therapy Management or Comprehensive Medication Management}

Impact on Clinical and Economic Outcomes. The Centers for Medicare \& Medicaid Services require Part D sponsors to provide a medication therapy management (MTM) program for beneficiaries. The value of MTM in populations other than Medicare beneficiaries remains unclear, and structured reimbursement for these services may be unavailable. ${ }^{13}$ In the numerous studies published on the topic, analysis is typically conducted for a specific population or type of intervention. ${ }^{14,15}$ Although the evidence to compare success across the various interventions is challenging, such comparisons would enable us to gain insights regarding the most effective and efficient interventions. Studies focusing on MTM services in a variety of patient populations are needed to identify which patients benefit most from these services.

\section{Broader Health Care Research Gaps}

\section{Additional Themes}

Other areas where managed care pharmacy professionals confront inadequate information surfaced during the Joint Research Committee's stakeholder-driven work. These topics were not included in the research agenda because the agenda highlights priorities that are relevant to managed care pharmacy, actionable within managed care pharmacy, and illustrate effects of patient care services delivered by managed care pharmacy. However, these are important evidentiary gaps to note, and AMCP and the AMCP Foundation are committed to partnering with others to close these gaps.

Additional topics that arose include interprofessional collaborations, behavioral outcomes, adherence, quality, pharmacy health information technology, digital health, and palliative care. In particular, topics related to comparative drug data in clinical trials surfaced as an additional key theme in both surveys.

\section{Comparative Drug Data}

In the KOL survey, $12 \%$ of respondents indicated that comparative drug data in clinical trials was a key gap, especially within oncology and biosimilars. In the second survey, $18 \%$ of respondents pointed to comparative drug data as a researchrelated need, with an emphasis on comparing products used to treat the same condition with different mechanisms of action.

Manufacturer-sponsored research is commonplace; however, these studies may not consistently use a comparative drug that is reflective of current medical practice. This can especially be true for newly launched drugs where initial studies are conducted for evaluation by the U.S. Food and Drug Administration to support approval. These studies do not necessarily meet the intent or purpose of MCOs' decision making, such as formulary placement or utilization management.
This can also be said for comparing drugs of the same mechanisms of action. One drug may show long-term clinical outcomes; however; clinical data are lacking to determine whether a class effect exists. True comparative effectiveness studies, which include total cost of care, are still needed.

\section{Agenda Activation and Continuous Review}

\section{Dissemination and Engagement Strategy}

AMCP and the AMCP Foundation are now advocating for the research initiatives to address these identified research needs. Primary target audiences are funders, researchers, AMCP members, and Foundation stakeholders. Researchers and potential researchers who can implement research in these areas are placed in academia as well as plans, pharmaceutical companies, and contract research organizations. Secondary target audiences are regulators and legislators, industry, patient advocates and advocacy organizations, and others.

We believe that our research agenda substantially overlaps with the interests of national agencies and charitable organizations, which can underwrite, facilitate, or encourage research in these areas. For example, MTM services and benefit design for the Medicare population touches on a population of core interest to the National Institute on Aging. ${ }^{16}$ Value-based decision making, value-based contracting, benefit design, and utilization management attempt to manage health care spending to achieve better value for money, an area of interest to multiple funders.

\section{Planned Reviews}

The research agenda and prioritization strategy will be annually reviewed by the Joint Research Committee to determine if modifications are warranted because of a change in landscape in managed care pharmacy or health care as a whole. At least every 3 years, the committee will initiate a stakeholder feedback process to revise as necessary.

\section{Conclusions}

Through surveying KOLs, AMCP members, and others, the Joint Research Committee identified evidentiary gaps critical to managed care pharmacy and developed a 4-part research agenda to highlight these gaps. To guide stakeholders in addressing the agenda, research topics were prioritized, and a dissemination and engagement strategy was developed to advocate for evidence generation. The agenda is intended to be broad and will continually evolve as the health care system changes, managed care pharmacy practitioners transform their work, and new technologies and data capabilities become available.

AMCP and the AMCP Foundation hope that this research agenda inspires the AMCP membership, researchers, and funding agencies to close these gaps in knowledge and understanding. It is imperative that managed care pharmacy's active role in generating evidence and partnering with the research community continues to grow, so we can fully activate a truly value-based health care system. 
Contributors from the Joint Research Committee of AMCP and the AMCP Foundation

JOSEPH COUTO, MBA, PharmD, Data Science Manager, Cigna Health Corporation; DESOLA DAVIS, PharmD, BCPS, BCACP, Drug Utilization Clinical Pharmacy Specialist, Kaiser Permanente Georgia; SCOTT DEVINE, PhD, Executive Director, US Evidence and Value Strategies, Merck \& Co.; PAULA EICHENBRENNER, MBA, CAE, Executive Director, AMCP Foundation; FAHIM FARUQUE, PharmD, Payer/Health-System Medical Information Fellow, Janssen Biotech; JODY GEMBARSKI, PharmD, Manager, Medical Drug Management and Customer Initiatives, BCBS Michigan; PATRICK GLEASON, PharmD, BCPS, FCCP, FAMCP, Assistant Vice President Health Outcomes, PRIME Therapeutics; JOSEPH GOBLE, PharmD, MSc, Senior Scientific Account Lead, Janssen; LAURA HAPPE, PharmD, MPH, Editor-in-Chief, Journal of Managed Care \& Specialty Pharmacy; JAN HANSEN, PhD, Vice President, Evidence for Access, Genentech; INMACULADA HERNANDEZ, PharmD, PhD, Assistant Professor, University of Pittsburgh; NEWELL MCELWEE, PharmD, MSPH, Vice President HEOR, Boehringer-Ingelheim; GARY MITCHELL OWENS, MD, President, Gary Owens Associates; AMBER REINERT, PharmD candidate, University of Missouri-Kansas City; MANDY RENFRO, PharmD candidate, The University of Texas at Austin College of Pharmacy; SOUMI SAHA, PharmD, JD, Senior Director Advocacy, Premier; KATHLEEN SHOEMAKER, MBA, PharmD, Senior Director, Strategic Alliances, Premier; DANIEL MARK TOMASZEWSKI, PharmD, PhD, Assistant Professor of Pharmacy Administration, Chapman University School of Pharmacy; AFTON WAGNER, PharmD, Director of Regulatory Affairs, AMCP; MARCUS WILSON, PharmD, President, HealthCore; KAREN WORLEY, PhD, Director of Internal Research, Humana; and KAI YEUNG, PharmD, PhD, Kaiser Permanente Washington Health Research Institute.

AUTHOR CORRESPONDENCE: Paula Eichenbrenner, MBA, CAE, Executive Director, AMCP Foundation, 675 N. Washington St., Alexandria, VA 22314. Tel.: 703.684.2605;

E-mail:paula@amcpfoundation.org.

\section{DISCLOSURES}

Chairs and members of the Joint Research Committee oversaw and conducted the work outlined in this report with the support of AMCP and the AMCP Foundation. No outside funding was received. Gembarski, Couto, Wilson, and Eichenbrenner declare no conflicts of interest, real or apparent, with any product or service mentioned in this report. Gembarski is employed by BCBS Michigan; Couto is employed by Cigna; Wilson is employed by HealthCore, a wholly owned subsidiary of Anthem; and Eichenbrenner is employed by the AMCP Foundation.

\section{ACKNOWLEDGMENTS}

AMCP and the AMCP Foundation acknowledge the leadership of Joint Research Committee Chairs Joseph Couto (2020-present), Jody Gembarski (2018-2020), and Marcus Wilson (2016-2018), as well as Susan A. Cantrell, $\mathrm{RPh}, \mathrm{CAE}$, Chief Executive Officer, AMCP.

\section{REFERENCES}

1. Cournoyer A. Payer survey: new findings on formulary decision making. Precision for Value. February 2018. Available at: http://www.precisionallaccess.com/external-data-and-formulary-decision-making-whats-the-connection/. Accessed January 29, 2020.

2. American College of Clinical Pharmacy. The research agenda of the American College of Clinical Pharmacy. Pharmacotherapy. 2007;27(2):312-24. Available at: https://onlinelibrary.wiley.com/doi/pdf/10.1592/phco.27.2.312. Accessed January 29, 2020.

3. Institute of Medicine, Roundtable on Value $\&$ Science-Driven Health Care. Appendix C: Comparative effectiveness research priorities: IOM recommendations (2009). In: Learning What Works: Infrastructure Required for Comparative Effectiveness Research: Workshop Summary. Washington, DC: National Academies Press; 2011. Available at: https://www.ncbi.nlm.nih.gov/ books/NBK64788/. Accessed January 29, 2020

4. Academy of Managed Care Pharmacy. Not happy with pharmacy research? Let's build a list of research priorities together! Webinar. October 22, 2014. Available at: https://www.amcp.org/Resource-Center/ real-world-evidence-research/not-happy-pharmacy-research-lets-build-listresearch?id=18663. Accessed February 12, 2020.

5. Reinert A, White A, Eichenbrenner P, et al. Top managed care pharmacy evidentiary gaps in 2017: a conventional content analysis. Poster presented at: AMCP Nexus 2017; October 16-19, 2017; Dallas, TX.

6. Reinert A, Gembarski J, Eichenbrenner P, et al. Refining a research agenda for managed care pharmacy: a survey across health care stakeholders. Poster presented at: AMCP Managed Care \& Specialty Pharmacy Annual Meeting 2019; March 25-29, 2018; San Diego, CA.

7. American Society of Association Executives. Create surveys that generate high-quality results. November/December 2015. Available at: https://www. asaecenter.org/resources/articles/an_magazine/2015/november-december/ create-surveys-that-generate-high-quality-results. Accessed January 29, 2020

8. People Pulse. Survey response rates. Tips on how to increase your survey response rates. Available at: https://www.peoplepulse.com/resources/usefularticles/survey-response-rates/. Accessed January 29, 2020

9. Katz R. Biomarkers and surrogate markers: an FDA perspective. NeuroRx. 2004;1(2):189-95. Available at: https://www.ncbi.nlm.nih.gov/pmc/articles/ PMC534924/pdf/neurorx001000189.pdf. Accessed January 29, 2020.

10. American Society of Clinical Oncology. Value in cancer care. ASCO value framework. Available at: https://www.asco.org/practice-policy/cancercare-initiatives/value-cancer-care. Accessed February 25, 2020.

11. Institute for Clinical and Economic Review. ICER value assessment framework. Available at: https://icer-review.org/methodology/icers-methods/ icer-value-assessment-framework-2/. Accessed February 25, 2020.

12. Academy of Managed Care Pharmacy Foundation. Trends in health care: disruptors and opportunities. Webinar. December 5, 2018. Available at: https://www.amcpfoundation.org/reports-research/amcp-foundation-webinar-archives/trends-health-care-disruptors-and-opportunities-summaryamcp-foundation-research-symposium. Accessed January 29, 2020.

13. Isetts B. Integrating medication therapy management (MTM) services provided by community pharmacists into a community-based accountable care organization (ACO). Pharmacy (Basel). 2017;5(4):56. Available at: https://www. ncbi.nlm.nih.gov/pmc/articles/PMC5748537/. Accessed January 29, 2020.

14. Viswanathan M, Kahwati LC, Golin CE, et al. Medication therapy management interventions in outpatient settings: a systematic review and metaanalysis. JAMA Intern Med. 2015;175(1):76-87. Available at: https://jamanetwork.com/journals/jamainternalmedicine/fullarticle/1935933. Accessed January 29, 2020

15. Ai A, Carretta H, Beitsch LM, et al. Medication therapy management programs: promises and pitfalls. J Manag Care Spec Pharm. 2014;20(12):1162-82. Available at: https://www.jmcp.org/doi/pdf/10.18553/jmcp.2014.20.12.1162. Accessed January 29, 2020.

16. National Institute on Aging. Division of Behavioral and Social Research. Available at: https://www.nia.nih.gov/research/dbsr. Accessed January 29, 2020. 